\title{
Can COVID-19 Increase the Risk of Herpes Zoster? A Narrative Review
}

\author{
Javier Diez-Domingo (D) - Raunak Parikh (D) - Amit B. Bhavsar (D) - \\ Elisa Cisneros (1) - Natalia McCormick (1) - Nicolas Lecrenier (1)
}

Received: March 22, 2021 / Published online: May 17, 2021

(C) GlaxoSmithKline Biologicals SA 2021, corrected publication 2021

\begin{abstract}
Herpes zoster (HZ) is associated with substantial morbidity. It is caused by reactivation of the latent varicella zoster virus (VZV) following decline in cell-mediated immunity, which is commonly age-related, but also occurs in individuals with immunosuppressive diseases and/ or treatment. Since coronavirus disease (COVID-19), caused by severe acute respiratory syndrome coronavirus 2 (SARS-CoV-2) infection, has been associated with $\mathrm{T}$ cell immune
\end{abstract}

Supplementary Information The online version contains supplementary material available at https:// doi.org/10.1007/s13555-021-00549-1.

J. Diez-Domingo

FISABIO-Public Health, Valencia, Spain

e-mail: javier.diez@fisabio.es

R. Parikh $(\bowtie) \cdot$ A. B. Bhavsar

GSK, Wavre, Belgium

e-mail: raunak.p.parikh@gsk.comA. B. Bhavsar

e-mail: amit.b.bhavsar@gsk.com

E. Cisneros - N. McCormick

GSK, Madrid, SpainE. Cisneros

e-mail: elisa.x.cisneros@gsk.comN. McCormick

e-mail: natalia.x.mccormick@gsk.com

N. Lecrenier

GSK, Rixensart, Belgium

e-mail: nicolas.lecrenier@gsk.com dysfunction and there have been reports of $\mathrm{HZ}$ in COVID-19 patients, we have performed a review of available literature on whether COVID-19 could trigger HZ. We identified 27 cases of HZ following COVID-19, which most frequently occurred within 1-2 weeks of COVID-19, and the majority of cases had typical presentation. Atypical presentations of $\mathrm{HZ}$ were noted especially in patients with lymphopenia. It has been hypothesized that VZV reactivation occurs as a consequence of $\mathrm{T}$ cell dysfunction (including lymphopenia and lymphocyte exhaustion) in COVID-19 patients. Based on current evidence, which is limited to case reports and case series, it is not possible to determine whether COVID-19 increases the risk of HZ. Practitioners should be aware of the possible increased risk of $\mathrm{HZ}$ during the pandemic period and consider timely therapeutic and preventive measures against it.

Keywords: COVID-19; Herpes zoster; Lymphopenia; SARS-CoV-2; Shingles; Cellmediated immunity 


\section{Key Summary Points}

Adults $>50$ years of age or those who have a weakened immune system are more vulnerable to developing herpes zoster (also known as shingles)

Coronavirus disease 2019 (COVID-19), caused by the SARS-CoV-2 virus, can weaken the immune system and lead to an increased risk of developing herpes zoster in this vulnerable population

Several cases of herpes zoster in patients with COVID-19 have been reported in the literature, but currently available data cannot confirm an increased occurrence

More research is needed to better understand whether there is an increased presence of herpes zoster in patients with COVID-19

Healthcare providers should be aware of this possibility during the COVID-19 pandemic and consider measures to prevent or treat herpes zoster

\section{DIGITAL FEATURES}

This article is published with digital features, including a summary slide, to facilitate understanding of the article. To view digital features for this article go to https://doi.org/10.6084/ m9.figshare.14438846.

\section{INTRODUCTION}

Herpes zoster (HZ) is caused by reactivation of the latent varicella zoster virus (VZV) [1]. It typically presents as a painful unilateral dermatomal rash associated with substantial morbidity and decline in quality of life. Reactivation is believed to follow a decline in VZV-specific cell-mediated immunity (CMI), which is most commonly age-related. As a result, a steady increase in the incidence rate is observed starting at 50 years of age with the highest incidence rates in individuals $>65$ years of age [2]. A decline in the CMI response due to immunosuppressive disease and/or treatment is also a known risk factor/trigger for HZ development. In the context of the coronavirus disease 2019 (COVID-19) pandemic, it is noteworthy that T cell immune dysfunction has been reported in patients with COVID-19 [3]. This includes lymphopenia [lower cluster of differentiation (CD) $4^{+}, \mathrm{CD}^{+}{ }^{+}, \mathrm{B}$ cells and natural killer (NK) cells], impaired lymphopoiesis, increased lymphocyte apoptosis and lymphocyte exhaustion.

While there have been several reports and short summaries on cases of $\mathrm{HZ}$ in patients with COVID-19, to our knowledge there is no comprehensive review on this subject $[4,5]$. We have undertaken the current study to raise awareness among practitioners and researchers about the possible association of COVID-19 and HZ by summarizing case reports since the pandemic onset, elaborating a possible biological basis related to how COVID-19 may trigger HZ and provide an assessment of the increased risk of $\mathrm{HZ}$ in patients with COVID-19 based on available evidence.

\section{METHODS}

Considering the limited but rapidly evolving emergence of scientific literature on $\mathrm{HZ}$ and COVID-19, a narrative review was undertaken. We performed a search in two databases (PubMed and Embase) with broad search terms ("Shingles," "Herpes zoster," and "COVID-19") in the English language during the period from 12 March 2020 to 31 December 2020. To identify publications on $\mathrm{HZ}$ in patients with COVID19 , all abstracts were first reviewed to identify relevant articles and then full-text availability. All full-text articles that included case reports of HZ patients with COVID-19 were included, and a descriptive analysis of the cases was performed.

\section{Compliance with Ethics Guidelines}

This article is based on previously conducted studies and does not contain any new studies 
with human participants or animals performed by any of the authors.

\section{RESULTS AND DISCUSSION}

The search strategy provided 76 and 33 hits from Embase and PubMed, respectively. Then, we reviewed the titles and abstracts of these searches to identify relevant articles. We identified 13 articles as relevant. We did not exclude any article on the basis of full-text review. The selected articles included $27 \mathrm{HZ}$ cases occurring after COVID-19. We included these cases in our analysis. Supplementary Table 1 provides an overview of clinical and laboratory case observations.

\section{Description of HZ Cases in Patients with COVID-19}

\section{Demographic and Co-Morbid Conditions}

Cases included both genders and were reported worldwide, including Europe (Italy, Spain), Asia (Saudi Arabia, China, India), Africa (Egypt), North America (United States) and South America (Brazil) [6-17]. There were cases with known risk factors for $\mathrm{HZ}$, which included age $>$ 50 years $(n=19)$, immunosuppressive therapies/immunomodulators $(n=2)$ and diabetes mellitus $(n=3)[5,7,8,10,11,13-17]$.

\section{COVID-19 Severity}

The severity of COVID-19 was varied. Most of the patients $(16 / 27)$ had an uncomplicated disease for which they received outpatient treatment; the remaining cases had pneumonia or hospitalization.

\section{Period Between Diagnosis of COVID-19 and $\mathrm{HZ}$}

The period between HZ and COVID-19 was available for 23 cases (see Fig. 1). In most of these cases $(n=13)$ HZ was diagnosed simultaneously or within the 1st week of COVID-19 diagnosis, with the remaining cases $(n=10)$ occurring within 10 weeks of COVID-19. For four other cases, $\mathrm{HZ}$ was diagnosed within a week after hospitalization for COVID-19 [16].

\section{Clinical Presentation of $\mathrm{HZ}$}

Most cases of $\mathrm{HZ}$ were diagnosed following a clinical examination by a dermatologist. In a few situations, the diagnosis was based on telemedicine consultations and photographs/ videos $[6,7,13]$. Supportive laboratory testing for $\mathrm{HZ}$ was available in a limited number of cases $[10,12,15]$.

In most cases, $\mathrm{HZ}$ had a typical presentation with lesions on the face [including herpes zoster ophthalmicus (HZO)], trunk, hips/buttocks or inguinal region. There were two cases of multidermatomal involvement, and three cases had necrotic features in otherwise healthy individuals $[5,17]$. Postherpetic neuralgia (PHN) was reported in one case [11].

Lymphopenia (or relative lymphopenia) was reported in several cases, including those with (1) multi-dermatomal involvement, (2) necrotic features or (3) HZ occurring 8-10 weeks following COVID-19 diagnosis [5, 11, 16, 17]. A low $\mathrm{CD}^{+} / \mathrm{CD}^{+}$ratio was reported in two cases and an increased interleukin (IL)- 6 level in one case $[5,17]$.

\section{Interpretation of Currently Available Clinical Evidence}

Since the clinical evidence of $\mathrm{HZ}$ occurrence in COVID-19 patients is limited to case reports and case series, it is necessary to consider the limitations of such data. Single case reports or case series are generally considered of low level of evidence. There is no comparator or control group, and they are not designed to assess risks. $\mathrm{HZ}$ is not an uncommon disease and will occur in a percentage of the population during the pandemic period. Furthermore, some risk factors for both diseases are shared (i.e., age, comorbid conditions, immunosuppression). Increased levels of stress and reduced exogenous boosting VZV (due to limited contact between elderly and young children) may also impact HZ occurrence during the pandemic period. Based on the available evidence, it is not possible to determine whether there has been any real HZ increase during the pandemic period or in patients with COVID-19. 


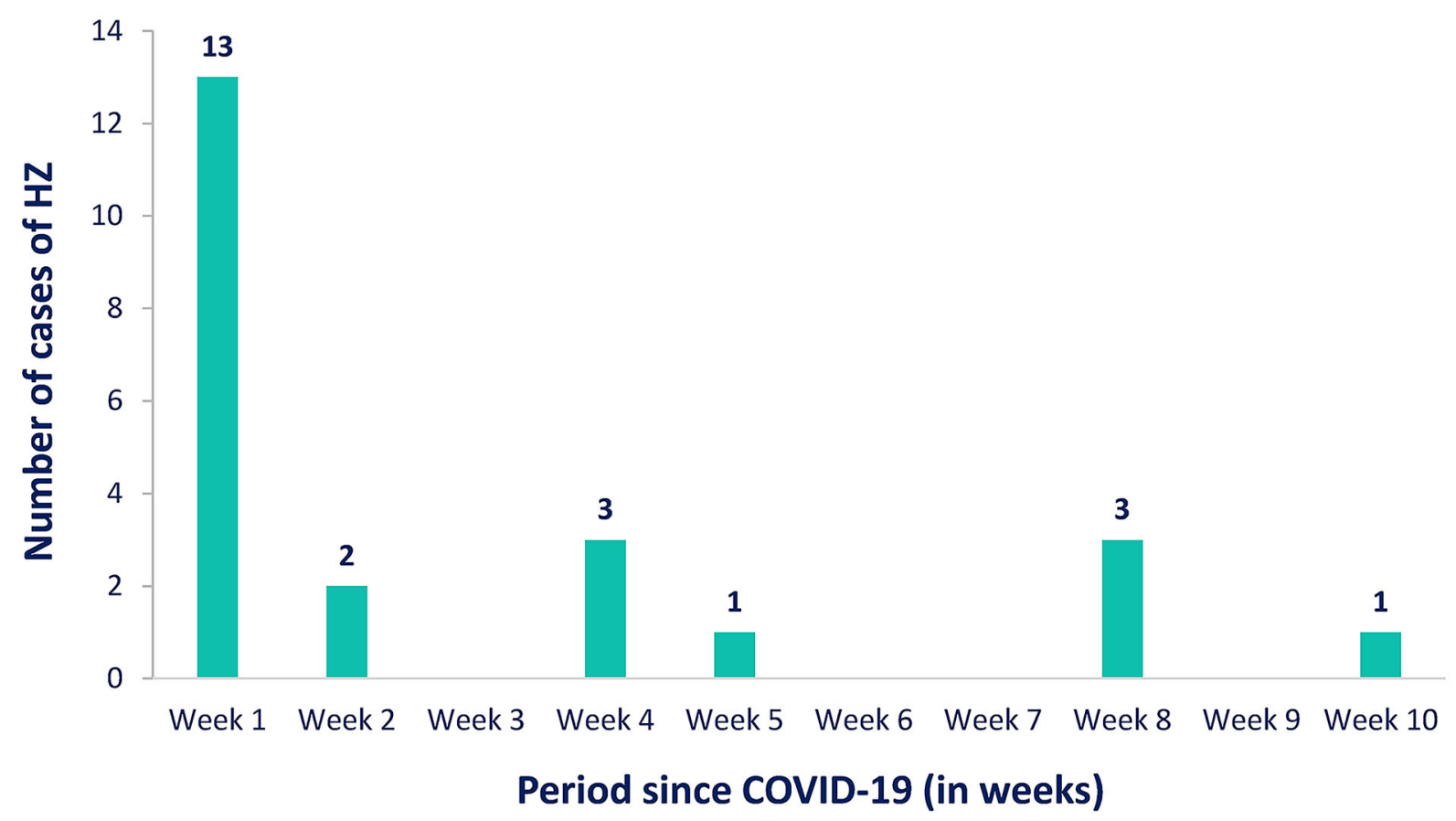

Fig. 1 Period until HZ diagnosis following COVID-19 $(N=23)[6-15,17]$

\section{Is There a Medical or Biological Basis for an Increased Risk of HZ in COVID-19 Patients?}

Resolution of primary infection by VZV is associated with the induction of VZV-specific memory $\mathrm{T}$ cells and persistence of VZV in the sensory ganglia [18]. This memory immune response is boosted periodically by exposure to varicella or silent reactivation of latent VZV. VZV-specific memory $T$ cells decline with age, and, as they decline below a threshold, there is an increased risk of HZ. While HZ reactivation is most commonly due to age-related decline in immunity, it can also occur in immunosuppressive conditions or treatments.

It has been hypothesized that since severe acute respiratory syndrome coronavirus 2 (SARS-CoV-2) infection can result in a wide range of $\mathrm{T}$ cell immune dysfunctions (including lymphopenia and lymphocyte exhaustion), it is during this period that the latent VZV reactivates [4]. Stress-induced reactivation of VZV has also been hypothesized $[6,12]$.

\section{Lymphopenia}

Lymphopenia has been reported in $>80 \%$ of COVID-19 cases, with some studies suggesting that it is more prominent in severe disease $[19,20]$. In a study that compared levels of peripheral lymphocyte subsets in hospitalized COVID-19 patients with healthy controls, COVID-19 patients had a significantly lower total lymphocytes, $\mathrm{CD} 4^{+} \mathrm{T}$ cells, $\mathrm{CD}^{+} \mathrm{T}$ cells, B cells and NK cells [21]. Possible causes of lymphopenia include:

- Lymphocytes express surface angiotensinconverting enzyme 2 (ACE2) receptors, and COVID-19 may be able to directly infect these cells with ultimate lysis.

- A marked increase in cytokines [including tumor necrosis factor- $\alpha$ (TNF- $\alpha$ ) and IL-6] during the cytokine storm may promote lymphocyte apoptosis and result in atrophy of lymphoid organs with reduced lymphocyte turnover.

- Lactic acidosis may inhibit lymphocyte proliferation [3, 20].

The significance of the lymphocyte count in $\mathrm{HZ}$ has been evaluated in a few studies. A study 
involving 192 patients with $\mathrm{HZ}$ and 28 controls showed that HZ patients had significantly lower levels of $\mathrm{CD}^{+}{ }^{-}$cells, $\mathrm{CD} 4^{+} \mathrm{T}$ cells and $\mathrm{CD}^{+} \mathrm{T}$ cells than the control group [22]. A similar observation was also made in another study that included 65 patients with ophthalmic zoster sine herpete (and 41 controls), in which patients with ophthalmic zoster sine herpete had significantly lower lymphocyte counts [23].

\section{Lymphocyte Exhaustion}

Functional studies have shown lymphocyte exhaustion with impairment of $\mathrm{CD}^{+}$helper $\mathrm{T}$ cells and $\mathrm{T}$ reg function as well as initial hyperactivation followed by a rapid exhaustion of $\mathrm{CD}^{+} \mathrm{T}$ cells [20]. Exhausting markers [e.g., CD94/ NK group 2 member A (NKG2A)] on cytotoxic cells (including $\mathrm{CD}^{+}{ }^{+} \mathrm{T}$ cells and $\mathrm{NK}$ cells) are upregulated, and multi-functional $\mathrm{CD}^{+}{ }^{+} \mathrm{T}$ cells [expressing at least 2 of the function-related cytokines interferon (INF)- $\gamma$, TNF- $\alpha$ and IL-2] significantly decreased in the severe vs. mild disease or in healthy individuals $[24,25]$.

While the above studies do suggest that COVID-19 impairs T cell function, the level and duration of immunosuppression needed to trigger HZ is not known. Studies in patients with Epstein-Barr-virus and cytomegalovirus infection suggest that transient immunosuppression may interfere with the latency of VZV, and in persons with human immunodeficiency virus (HIV), the level of immunosuppression (CD4 cell count $<500$ cell $/ \mathrm{mm}^{3}$ ) has been shown to increase risk for HZ [26-29].

\section{What Type of Clinical/Epidemiological Evidence Is Needed to Assess Whether There Has Been an Increase in HZ Cases During the COVID-19 Pandemic?}

Since there is a possible biological basis for SARS-CoV-2 infection triggering $\mathrm{HZ}$ and this can explain an increased risk of $\mathrm{HZ}$ in patients with COVID-19, there is a need to evaluate HZ cases during the pandemic period with welldesigned studies. Studies could assess either the risk of $\mathrm{HZ}$ in patients with COVID-19 or HZ trends during the pandemic. Studies designed to assess the risk of $\mathrm{HZ}$ in patients with and without COVID-19 during the pandemic period could assess whether there has been an increased risk of HZ in patients with COVID-19. Both case-control and retrospective cohort studies can be considered. Cases and controls need to be matched. Studies designed to assess $\mathrm{HZ}$ trends during the pandemic vs. pre-pandemic period may provide an understanding of broad trends in the population but cannot specifically determine whether a change in trends was due to COVID-19 or another cause. Studies can evaluate the incidence rate in the general population or the occurrence of $\mathrm{HZ}$ in specific populations (e.g., administrative or hospital databases). Interestingly, a descriptive analysis of $\mathrm{HZ}$ diagnosis in the Brazilian public health system identified a $35.4 \%$ increase in $\mathrm{HZ}$ diagnosis during the pandemic period (March to August 2020) versus the comparable period in 2017-2019 (Fig. 2) [30]. This should be interpreted with caution, as this does not provide direct evidence that the increase has been due to COVID-19.

There are a few pandemic-related factors that need to be considered when designing a study, as they may influence the detection/confirmation of cases and hence the study outcomes. These include the assessment of access to medicines, healthcare-seeking behavior during the pandemic period, telemedicine consultations, COVID-19 testing protocols and government-mandated control measures including lockdowns. There have been substantial variations in these factors during the pandemic across regions and time periods, and it is critical to understand their impact on the study design and outcome.

\section{CONCLUSION}

HZ causes substantial morbidity and commonly affects older adults. We have noted numerous case reports of HZ in patients with COVID-19. Most of these HZ cases occurred within weeks of COVID-19 and had a typical presentation. There were a few cases with atypical presentations that are commonly seen in immunocompromised individuals. Considering the 


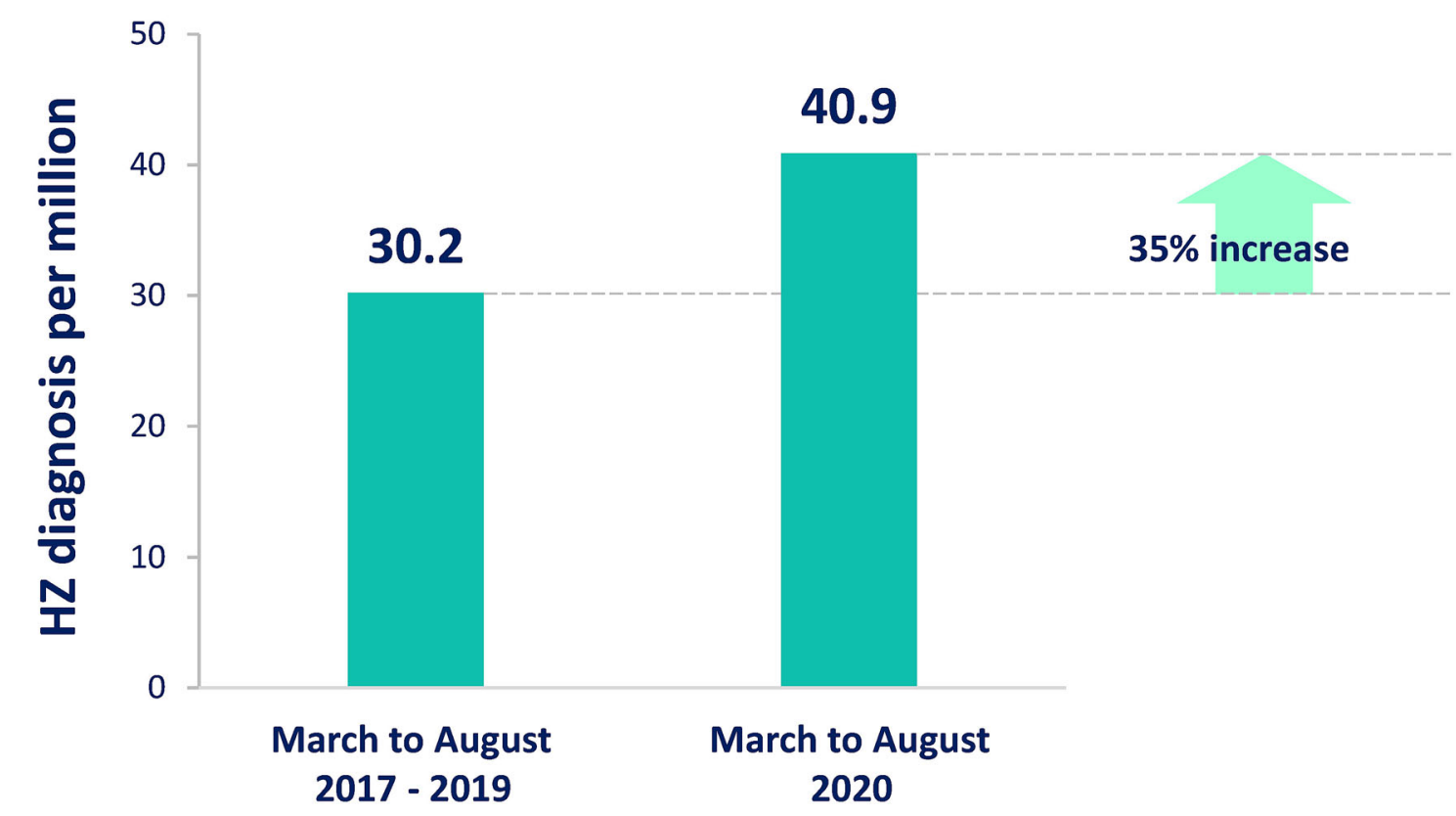

Fig. 2 Average per million inhabitants with herpes zoster (HZ) diagnoses reported by the Brazilian public health system in all geographical regions between March and August 2017-2019 compared to the same period in 2020 [30]

limitations in case report interpretation, and based on current evidence, it is not possible to determine whether COVID-19 increases the risk of HZ. However, there is a possible biological basis for an increase in the risk of HZ in COVID19 patients. Further research in the form of welldesigned studies is needed to assess this association. Practitioners should be aware of the possible increased risk of $\mathrm{HZ}$ during the pandemic period and consider timely therapeutic and preventive measures against $\mathrm{HZ}$.

\section{ACKNOWLEDGEMENTS}

Funding. GlaxoSmithKline Biologicals SA funded this research. GlaxoSmithKline Biologicals SA also covered all costs associated the publication of this manuscript.

Editorial and Other Assistance. The authors would like to thank the Business \& Decision Life Sciences platform for editorial assistance and manuscript coordination on behalf of GSK. Elena Chaves Rodriguez coordinated manuscript development and provided editorial support.

Authorship. All named authors meet the International Committee of Medical Journal Editors (ICMJE) criteria for authorship for this article, take responsibility for the integrity of the work as a whole, and have given their approval for this version to be published.

Authorship Contributions. All authors had the idea for the article. $\mathrm{RP}$ and $\mathrm{AB}$ performed the literature search and data analysis. All authors drafted and critically revised the work.

Disclosures. Amit B. Bhavsar, Elisa Cisneros, Nicolas Lecrenier, Natalia McCormick and Raunak Parikh are employees of the GSK group of companies. Javier Diez-Domingo reports grants from the GSK group of companies outside of the submitted work. Nicolas Lecrenier reports personal fees from the GSK group of companies during and outside the submitted work. Raunak Parikh and Elisa Cisneros hold shares from the GSK group of companies. Amit B. Bhavsar, Elisa Cisneros, Javier Diez-Domingo, Nicolas Lecrenier, Natalia McCormick and 
Raunak Parikh declare no other financial and non-financial relationships and activities.

Compliance with Ethics Guidelines. This article is based on previously conducted studies and does not contain any new studies with human participants or animals performed by any of the authors.

Open Access. This article is licensed under a Creative Commons Attribution-NonCommercial 4.0 International License, which permits any non-commercial use, sharing, adaptation, distribution and reproduction in any medium or format, as long as you give appropriate credit to the original author(s) and the source, provide a link to the Creative Commons licence, and indicate if changes were made. The images or other third party material in this article are included in the article's Creative Commons licence, unless indicated otherwise in a credit line to the material. If material is not included in the article's Creative Commons licence and your intended use is not permitted by statutory regulation or exceeds the permitted use, you will need to obtain permission directly from the copyright holder. To view a copy of this licence, visit http://creativecommons.org/licenses/by$\mathrm{nc} / 4.0 /$.

\section{REFERENCES}

1. Rosamilia LL. Herpes Zoster presentation, management, and prevention: a modern case-based review. Am J Clin Dermatol. 2020;21(1):97-107.

2. Kawai K, Gebremeskel BG, Acosta CJ. Systematic review of incidence and complications of herpes zoster: towards a global perspective. BMJ Open. 2014;4(6):e004833.

3. Tavakolpour S, Rakhshandehroo T, Wei EX, Rashidian M. Lymphopenia during the COVID-19 infection: What it shows and what can be learned. Immunol Lett. 2020;225:31-2.

4. Wang B, Guo S, Yao Y, Li Y, Zhang G. Dermatologists may need to pay more attention to herpes zoster during the pandemic of COVID-19. Infect Dis. 2020. https://doi.org/10.1080/23744235.2020. 1797158.
5. Brambilla L, Maronese C, Tourlaki A, Veraldi S. Herpes zoster following COVID-19: a report of three cases. Eur J Dermatol. 2020;30(6):754-6.

6. Shors AR. Herpes zoster and severe acute herpetic neuralgia as a complication of COVID-19 infection. JAAD Case Rep. 2020;6(7):656-7.

7. Elsaie ML, Nada HA. Herpes zoster (shingles) complicating the course of COVID19 infection. J Dermatol Treat. 2020. https://doi.org/10.1080/ 09546634.2020.1782823.

8. Elsaie ML, Youssef EA, Nada HA. Herpes Zoster might be an indicator for latent COVID 19 infection. Dermatol Ther. 2020;33(4):13666.

9. Nofal A, Fawzy MM, El Sharaf DSM, El-Hawary EE. Herpes Zoster ophthalmicus in COVID-19 patients. Int J Dermatol. 2020;59(12):1545-6.

10. Xu R, Zhou Y, Cai L, Wang L, Han J, Yang X, et al. Co-reactivation of the human herpesvirus alpha subfamily (herpes simplex virus- 1 and varicella zoster virus) in a critically ill patient with COVID19. Br J Dermatol. 2020;183(6):1145-7.

11. Cao X, Zhang X, Meng W, Zheng H. Herpes Zoster and postherpetic neuralgia in an elderly patient with critical COVID-19: a case report. J Pain Res. 2020;13:2361-5.

12. Ferreira A, Romão TT, Macedo YS, Pupe C, Nascimento OJM. COVID-19 and Herpes Zoster co-infection presenting with trigeminal neuropathy. Eur J Neurol. 2020;27(9):1748-50.

13. Pona A, Jiwani RA, Afriyie F, Labbe J, Cook PP, Mao Y. Herpes Zoster as a potential complication of coronavirus disease 2019. Dermatol Ther. 2020;33(6):13930.

14. Saati A, Al-Husayni F, Malibari AA, Bogari AA, Alharbi M. Herpes Zoster co-infection in an immunocompetent patient with COVID-19. Cureus. 2020;12(7):8998.

15. Fernandez-Nieto D, Ortega-Quijano D, Suarez-Valle A, Burgos-Blasco P, Jimenez-Cauhe J, FernandezGuarino M. Comment on: to consider varicella-like exanthem associated with COVID-19, virus varicella zoster and virus herpes simplex must be ruled out. Characterization of herpetic lesions in hospitalized COVID-19 patients. J Am Acad Dermatol. 2020;83(3):257-9.

16. Tartari F, Spadotto A, Zengarini C, Zanoni R, Guglielmo A, Adorno A, et al. Herpes Zoster in COVID-19-positive patients. Int $\mathrm{J}$ Dermatol. 2020;59(8):1028-9. 
17. Bhargava P, Singdia H, Mathur R, Garg R, Rani N, Nijhawan S, et al. Herpes Zoster duplex unilateralis as a manifestation of severe lymphopenia in COVID19. Eur J Pain. 2020;25(2):508-9.

18. Arvin A. Aging, immunity, and the varicella-zoster virus. N Engl J Med. 2005;352(22):2266-7.

19. Debuc B, Smadja DM. Is COVID-19 a new hematologic disease? Stem Cell Rev Rep. 2021;17(1):4-8.

20. Terpos E, Ntanasis-Stathopoulos I, Elalamy I, Kastritis E, Sergentanis TN, Politou M, et al. Hematological findings and complications of COVID-19. Am J Hematol. 2020;95(7):834-47.

21. Wang F, Nie J, Wang H, Zhao Q, Xiong Y, Deng L, et al. Characteristics of peripheral lymphocyte subset alteration in COVID-19 pneumonia. J Infect Dis. 2020;221(11):1762-9.

22. Wei L, Zhao J, Wu W, Zhang Y, Fu X, Chen L, et al. Decreased absolute numbers of CD3(+) T cells and CD8(+) $\mathrm{T}$ cells during aging in herpes zoster patients. Sci Rep. 2017;7(1):15039.

23. Marumoto T, Hiratsuka Y, Murakami A. The significance of the determination of lymphocytes with clinical manifestation of ophthalmic zoster sine herpete. Clin Ophthalmol (Auckland, NZ). 2010;4: 817-22.

24. Zheng HY, Zhang M, Yang CX, Zhang N, Wang XC, Yang XP, et al. Elevated exhaustion levels and reduced functional diversity of $\mathrm{T}$ cells in peripheral blood may predict severe progression in COVID-19 patients. Cell Mol Immunol. 2020;17(5):541-3.

25. Xu B, Fan CY, Wang AL, Zou YL, Yu YH, He C, et al. Suppressed $\mathrm{T}$ cell-mediated immunity in patients with COVID-19: a clinical retrospective study in Wuhan, China. J Infect. 2020;81(1):e51-60.

26. Blank LJ, Polydefkis MJ, Moore RD, Gebo KA. Herpes Zoster among persons living with HIV in the current antiretroviral therapy era. J Acquir Immune Defic Syndr. 2012;61(2):203-7.

27. Dworkin RH, Johnson RW, Breuer J, Gnann JW, Levin MJ, Backonja M, et al. Recommendations for the management of herpes zoster. Clin Infect Dis. 2007;44:S1-26.

28. Ogunjimi B, Hens N, Pebody R, Jansens H, Seale H, Quinlivan M, et al. Cytomegalovirus seropositivity is associated with Herpes Zoster. Hum Vaccin Immunother. 2015;11(6):1394-9.

29. Karner W, Bauer G. Activation of a varicella-zoster virus-specific IgA response during acute EpsteinBarr virus infection. J Med Virol. 1994;44(3): 258-62. https://doi.org/10.1002/jmv.1890440308.

30. Maia CMF, Marques NP, de Lucena EHG, de Rezende LF, Martelli DRB, Martelli-Júnior $\mathrm{H}$. Increase in the number of Herpes Zoster cases in Brazil related to the COVID-19 pandemic. Int J Infect Dis. 2021;104:732-3. 